\title{
The role of dynamic modelling in understanding the microbial contribution to rumen function
}

\author{
Jan Dijkstra $^{1 *}$, Jonathan A. N. Mills ${ }^{2}$ and James France ${ }^{2}$ \\ ${ }^{1}$ Animal Nutrition Group, Wageningen Institute of Animal Sciences, Wageningen University, \\ Marijkeweg 40, 6709 PG Wageningen, The Netherlands \\ ${ }^{2}$ The University of Reading, Department of Agriculture, Earley Gate, Reading RG6 6AT, UK
}

Mechanistic models of microbial metabolism in the rumen aim at an improved understanding and integration for research purposes or at an improved prediction for practical purposes. The standard way of representing such models is the rate: state formalism. The system is defined by a number of state variables and a set of differential equations describe the change of the state variables with time. Three different types of solution to these dynamic models are distinguished, and examples of these solutions are described to illustrate the applications and contributions of dynamic modelling in the study of the rumen microbial ecosystem. Type I solutions are obtained when the system is in steady state and the differential equations are solved by setting the differentials to zero. An application of the type I solution is the indirect approach to quantifying the fibrolytic anaerobic fungi in the rumen. The solutions of the model describing the alternate life cycle of rumen fungi, with its free-swimming dispersal and particle-attached stages, appear to be consistent with ruminal and faecal observations. Type II solutions are obtained when the system is not in steady state but the differential equations can be integrated analytically. An application of this type of solution is the quantification of the growth and growth yield in batch cultures. Such models help to quantify the degradation of substrates in the rumen and to elucidate the interactions between groups of rumen micro-organisms. Type III solutions are obtained when the system is not in steady state and when the differential equations have to be solved numerically. Applications of the type III solutions are the rumen simulation models that describe substrate degradation, endproduct formation and microbial metabolism in an integrated manner. To illustrate this type III solution, a model of lactic acid metabolism in the rumen is defined, and its contribution to understanding of the paths and rates of lactic acid disappearance described. It is essential that the models are based

\footnotetext{
Abbreviations: $\mathrm{Ba}_{\mathrm{LP}}$, amylolytic lactic acid-producing bacteria; $\mathrm{Ba}_{\mathrm{LU}}$, amylolytic lactic acid-utilizing bacteria; ODE, ordinary differential equations; OM, organic matter; Po, protozoa; VFA, volatile fatty acids.

*Corresponding author: Dr Jan Dijkstra, fax +31 317 484260, email jan.dijkstra@alg.vv.wau.nl
} 
on sound mathematical and biological principles. However, the various applications described in the paper show that models need not necessarily be complex and very detailed to contribute to better understanding.

\section{Rumen micro-organisms: Modelling}

\section{Introduction}

Ruminants are dependent largely upon micro-organisms in the reticulo-rumen ('rumen') for the degradation of ingested plant material. The micro-organisms supply the host animal with endproducts of fermentation, particularly volatile fatty acids (VFA) that are absorbed mainly through the rumen wall. Besides, microbial protein is usually the most important source of amino acids that are available for the metabolism of the host. A morphologically and functionally diverse population of micro-organisms is present in the rumen. The microbial species present include eubacteria, archae, protozoa and fungi. A recent collection of reviews on the microbial population and activities in the rumen has been edited by Hobson \& Stewart (1997). Rumen micro-organisms differ widely in substrates that they ferment and in endproducts that they form, whilst interactions between micro-organisms will also affect the rumen fermentation. For example, interspecies hydrogen transfer between hydrogen-producing bacteria, protozoa and fungi and hydrogen-utilizing methanogenic archae may increase acetate production and decrease production of intermediates such as succinate and ethanol (Wolin et al. 1997). Predation on bacteria by ciliate and flagellate protozoa may reduce the outflow of microbial biomass and availability of amino acids from digested microbial protein (Williams \& Coleman, 1997). Thus, this diversity gives rise to large differences in rate and extent of feed degradation, amount and type of VFA formed, and amount and composition of microbial material that is washed out from the rumen, and ultimately to differences in production level, product composition and excretion of waste material.

As qualitative knowledge of microbial metabolism in the rumen increased, quantitative approaches were developed. These quantitative approaches generally aim at an improved prediction of fermentation in the rumen for practical purposes (for example, microbial representations in protein evaluation systems; Dijkstra et al. 1998a) or at an improved understanding and integration for research purposes (France et al. 1998). Quantitative approaches may be broadly classified into empirical and mechanistic models (France \& Thornley, 1984). Empirical models use experimental data to quantify relationships directly. In contrast, mechanistic models are constructed by examining the structure of a system and analysing the behaviour of the system in terms of its individual components and their interactions. Here on, we confine our attention to dynamic mechanistic models, as we believe this has the most to offer understanding of the microbial contribution to rumen function.

\section{Mathematical description of mechanistic models}

The majority of dynamic mechanistic models appearing in the nutritional literature are based on systems of ordinary differential equations (ODE). There is a mathematically standard way of representing such models called the rate : state formalism (France \& Thornley, 1984). The system under investigation is defined at time $t$ by $q$ state variables: $X_{1}, X_{2}, \ldots, X_{q}$. These variables represent properties or attributes of the system (for example, microbial mass, quantity of sub- 
strate). The model then comprises $q$ first-order ODE which describe how the state variables change with time:

$$
\mathrm{d} X_{i} / \mathrm{d} t=f_{i}\left(X_{1}, X_{2}, \ldots, X_{q} ; P\right) ; i=1,2, \ldots, \mathrm{q},
$$

where $P$ denotes a set of parameters, and the function $f_{i}$ gives the rate of change of the state variable $X_{i}$. The function $f_{i}$ comprises terms which represent the rates of component processes (for example, microbial synthesis, substrate utilization) with dimensions of state variable per unit time, and these rates can be calculated from the state variables alone, with of course the values of any parameters and constants. In this type of mathematical modelling, the differential equations are formed through direct application of the laws of science (for example, the law of mass conservation, the first law of thermodynamics) or by application of a continuity equation derived from more fundamental scientific laws.

There are three types of solution to these dynamic models: (i) the system under investigation is in steady state and solutions are obtained by setting the differentials to zero, manipulating, and solving the resultant algebraic expressions (type I solution); (ii) the system is in non-steady state and the ODE are linear and can be integrated analytically to give an expression for each state variable (type II); (iii) the system is in non-steady state but the ODE are non-linear and have to be integrated numerically (type III). In the present paper, we illustrate applications and contributions of dynamic modelling based on the rate : state formalism in the study of the rumen microbial ecosystem with type I, II and III solutions. The applications described are: (i) an indirect approach to quantifying the fibrolytic anaerobic fungi in the rumen (France et al. 1990) (type I solution); (ii) quantifying the growth and growth yield in batch cultures and in the rumen using Monod and Pirt equations (Monod, 1942; Pirt, 1965, 1975) (type II); (iii) quantifying the microbial contribution to microbial protein synthesis and to lactate production and utilization based on the rumen simulation models of Baldwin et al. (1987) and Dijkstra et al. (1992) (type III).

\section{Quantifying rumen fungi}

In the rumen, populations of anaerobic fungi can remain viable indefinitely (Gordon \& Phillips, 1998). The life cycle of anaerobic fungi is generally considered to consist of two distinct stages, in which free-swimming zoospores in rumen liquid alternate with particle-attached fungal thalli. Both stages must co-exist in order for fungal populations to achieve perpetual viability in the rumen. Furthermore, because of the continuous nature of the rumen ecosystem, growth of fungal biomass in the rumen must balance the loss of fungi by death and passage from the rumen. Thus, it follows that a non-trivial relationship must exist between the numbers of zoospores and thalli which inhabit the rumen.

Several procedures have been developed for enumerating fungal populations in the rumen (Mountfort \& Orpin, 1995). These are mostly limited, however, to the enumeration of zoospores, either by direct counting after dilution from rumen liquid, or indirectly from the number of colonies which develop in cellobiose-containing roll tubes. A lesser-used technique, which does not provide an absolute cell count but can be used to compare thallus populations, is to count the number of zoosporangia associated with leaf blades or impregnated agar strips after in vitro or in sacco incubation in rumen liquid. An enumeration procedure based upon most probable numbers is also available. This technique does not distinguish between stages of the life cycle, but fungal populations can be enumerated, as thallus forming units, relative to their ability to degrade plant cell walls. Thus, whilst enumeration procedures are available to 
quantify fungal populations, none is wholly suitable for the enumeration of fungal thalli. Recent techniques, which have to be developed further, make use of ribosomal specific oligonucleotides to measure total fungal populations (for example, Krause et al. 1999).

An alternative approach to enumerate fungal populations is that of mathematical modelling. The size of the zoospore and thallus populations is likely to be dependent on a variety of factors in the rumen, including substrate type and availability, the respective swimming and encystment times of zoospore and thallus populations, the maturation time of fungal thalli, the yield of zoospores from mature thalli and the flow properties of liquid and solids from the rumen. Based on a knowledge of these factors, the development of a mathematical model to predict the number of substrate-associated thalli from the concentration of zoospores in rumen liquid is described below (for full details, see France et al. 1990).

\section{Model construction}

To illustrate how data and hypotheses are translated into a mechanistic model, we will describe the various steps and equations of the fungal life cycle model. In this model, the life cycle of anaerobic fungi (Fig. 1) is partitioned such that the rumen population, $X$, is considered in terms of three mutually exclusive sub-populations $X_{1}, X_{2}$ and $X_{3} . X_{1}$ denotes the number of free-swimming zoospores (those in the first phase of their life cycle), $X_{2}$ the number of particle-attached thalli undergoing vegetative growth before septation (the second phase of the cycle), and $X_{3}$ the number of mature, particle-attached thalli between septation and zoosporulation (the third phase). It is assumed that the time spent in each phase of the life cycle (by those individuals that will enter the next phase) follows an exponential distribution with respective known means $\lambda_{1}, \lambda_{2}$ and $\lambda_{3}$ (all h). On completion of the life cycle after zoosporogenesis, $Y$ motile zoospores per zoosporangium are released back into the liquid medium.

The state variables $X_{1}, X_{2}$ and $X_{3}$ are depicted as compartments (boxes) within the rumen, and the fluxes between compartments and out of the system as arrowed lines (Fig. 2). Fungi in the first phase of their life cycle are assumed to leave the rumen with the passage of liquid digesta to the lower gut, and those in the second and third phases with the passage of particulate digesta. All passage is taken to be a first-order process with a rate constant $k_{1}$ for liquid and $k_{2}$ for particulate matter (both $/ \mathrm{h}$ ). Similarly, death in each phase is assumed first order with respective rate constants $d_{1}, d_{2}, d_{3}$ (all $/ \mathrm{h}$ ). The rate constant pertaining to each flux is shown against the corresponding arrowed line $\left(c_{i}\right.$, the rate constants for transfer, equal $\left.\lambda_{i}{ }^{-1}\right)$.

Applying the principle of mass conservation, the differential equations describing the dynamics of this system are:

$$
\begin{aligned}
& \mathrm{d} X_{1} / \mathrm{d} t=\lambda_{3}^{-1} Y X_{3}-\left(k_{1}+d_{1}+\lambda_{1}^{-1}\right) X_{1}, \\
& \mathrm{~d} X_{2} / \mathrm{d} t=\lambda_{1}^{-1} X_{1}-\left(k_{2}+d_{2}+\lambda_{2}^{-1}\right) X_{2}, \\
& \mathrm{~d} X_{3} / \mathrm{d} t=\lambda_{2}^{-1} X_{2}-\left(k_{2}+d_{3}+\lambda_{3}^{-1}\right) X_{3} .
\end{aligned}
$$

These differential equations satisfy the rate : state formalism (compare with equation 1). Under the assumption of steady-state conditions in the rumen, equations (2) equate to zero (type I solution). For a non-trivial steady-state solution, the rate constants and yield factor must satisfy the following condition, namely:

$$
\left(k_{1}+d_{1}+\lambda_{1}^{-1}\right)\left(k_{2}+d_{2}+\lambda_{2}^{-1}\right)\left(k_{2}+d_{3}+\lambda_{3}^{-1}\right)-\lambda_{1}^{-1} \lambda_{2}^{-1} \lambda_{3}^{-1} Y=0 .
$$

Numerical solutions to equation (3) for the parameters $d_{1}, d_{2}, d_{3}, k_{1}, k_{2}, \lambda_{1}, \lambda_{2}, \lambda_{3}$ and $Y$ (all $>0$ ) can be obtained by imposing an appropriate (representative) range on each of these parameters 


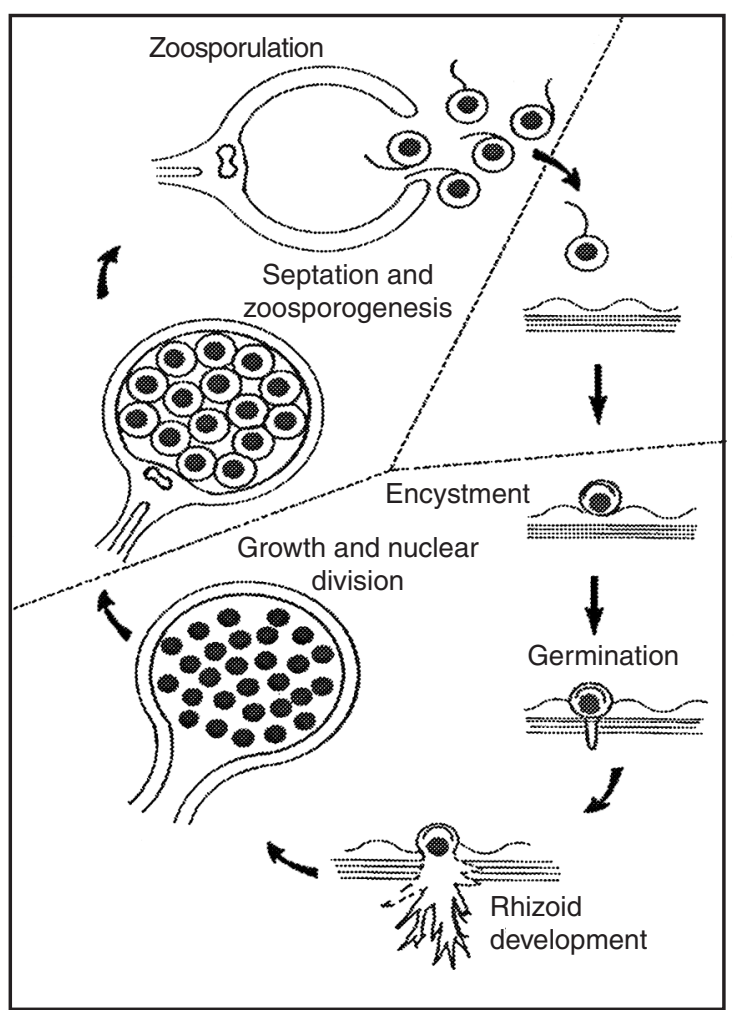

Fig. 1. Diagrammatic representation of the life cycle of monocentric rumen fungi. The cycle is partitioned into three sections representing populations of zoospores, immature thalli and mature thalli, respectively $(---)$, for translation into a mathematical model. (Reproduced by permission of Academic Press.)

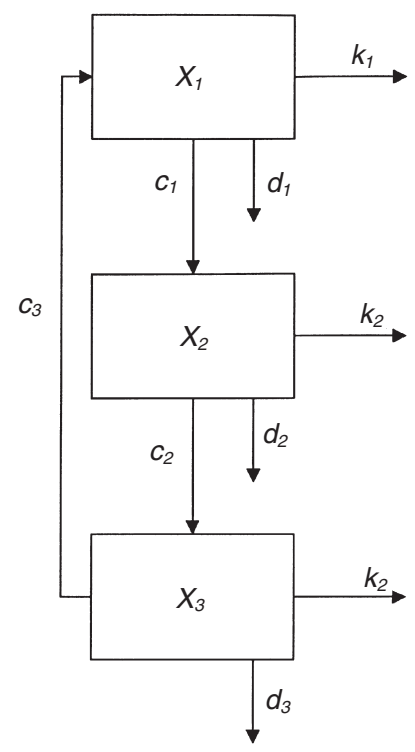

Fig. 2. Compartmental scheme for estimating the population of anaerobic fungi in the rumen using a type I solution model of fungi in the rumen. The three compartments $X_{1}, X_{2}$ and $X_{3}$ represent populations of zoospores, immature thalli and mature thalli, respectively. $(\rightarrow$ ), Fluxes; the rate constant pertaining to each flux is shown against the corresponding arrowed line. (Reproduced by permission of Academic Press.) 
and solving iteratively using the Newton-Raphson method (for details, see France et al. 1990). The motile population $X_{1}$ can be calculated from the concentration of zoospores in rumen liquid, $C_{X_{1}}$ (zoospores $\left./ \mathrm{ml}\right)$, and the rumen liquid volume, $V(\mathrm{ml})$ :

$$
X_{1}=C_{X_{1}} V \text {. }
$$

Having determined appropriate values for the parameters $d_{1}, d_{2}, d_{3}, k_{1}, k_{2}, \lambda_{1}, \lambda_{2}, \lambda_{3}$ and $Y$ by solving equation (3) numerically, the thallus populations $X_{2}$ and $X_{3}$ can then be evaluated using equations (2.1) and (2.2) equated to zero as follows:

$$
\begin{gathered}
X_{2}=\lambda_{1}^{-1} X_{1} /\left(k_{2}+d_{2}+\lambda_{2}^{-1}\right), \\
X_{3}=\left(k_{1}+d_{1}+\lambda_{1}^{-1}\right) X_{1} /\left(\lambda_{3}^{-1} Y\right) .
\end{gathered}
$$

The total number of anaerobic fungi in the rumen is given by the sum:

$$
X=X_{1}+X_{2}+X_{3} \text {. }
$$

Therefore, the total population of anaerobic fungi, together with the number in each phase of the life cycle, can be estimated by solving equations (3) to (6) with appropriate bounds.

This description illustrates the contribution of modelling to science by providing a structure within which to generate and evaluate hypotheses. The construction of the flow diagram links several parts of the system and forces the researcher to develop research hypotheses. The conceptual framework helps to pinpoint areas where knowledge is lacking, stimulating new ideas and experimental approaches. In the next section, the contribution of modelling to quantitative evaluation of the hypotheses is demonstrated.

\section{Model application}

The life cycles of several monocentric rumen fungi have been described (for example, Neocallimastix patriciarum, $N$. frontalis, $N$. hurleyensis, Piromonas communis, Sphaeromonas communis, Caecomyces equi) (for review, see Mountfort \& Orpin, 1995). Nonetheless, there is insufficient quantitative information in the literature to ascribe exact values, or even accurate ranges, to all the life-cycle parameters for any individual species of rumen fungus. Therefore, parameter ranges appropriate to rumen fungi generally have to be adopted. A review of the literature suggests the following ranges for the life-cycle parameters: $0.25 \leqslant \lambda_{1} \leqslant 4 \mathrm{~h}, 6 \leqslant \lambda_{2}$ $\leqslant 24 \mathrm{~h}, 0.25 \leqslant \lambda_{3} \leqslant 18 \mathrm{~h}$, and $10 \leqslant Y \leqslant 120 \mathrm{~h}$ (France et al. 1990). Information on the fractional rate parameters is uneven. Data in the literature on which to base ranges for the death rates are very sparse, seemingly confined to Theodorou et al. (1990). These data imply the ranges $0.009 \leqslant d_{1} \leqslant 0.015 / \mathrm{h}, 0 \leqslant d_{2} \leqslant 0.14 / \mathrm{h}$, and $0 \leqslant d_{3} \leqslant 0.14 / \mathrm{h}$. The literature on ruminal passage rates for liquid and solids, however, is more extensive (for review, see Dhanoa et al. 1989), suggesting the ranges $0.041 \leqslant k_{1} \leqslant 0.12 / \mathrm{h}$, and $0.020 \leqslant k_{2} \leqslant 0.051 / \mathrm{h}$.

Solving equations (3) to (6) numerically subject to these bounds using the NewtonRaphson method with $X_{1}$ set at unity yields $X_{2}=1 \cdot 3$ and $X_{3}=0 \cdot 4$. This solution suggests that in a population of anaerobic fungi, the number of immature and mature particle-attached thalli is about $70 \%$ greater than the population of free-swimming zoospores. An alternative solution, obtained by imposing tighter restrictions on the life-cycle parameters (i.e. $0 \cdot 15 \leqslant \lambda_{1} \leqslant 1,18 \leqslant$ $\lambda_{2} \leqslant 24,3 \leqslant \lambda_{3} \leqslant 6$ and $40 \leqslant Y \leqslant 80$ ), yields $X_{2}=0.46$ and $X_{3}=0.081$ (see France $e t$ al. 1990). In this solution, the total particle-attached population is approximately $54 \%$ of the population of free-swimming zoospores. Theodorou et al. (1990) describe an experiment in which four British Friesian steers (average live weight $223 \mathrm{~kg}$ ) were fed ad libitum on chopped 
perennial ryegrass hay supplemented with concentrates, and the volume and zoospore concentration of their rumens were measured. Applying these solutions to that experiment gives values of $7.5 \times 10^{8}$ for the free-swimming zoospore population in the rumen and 4.0-12.6 $\times 10^{8}$ for the number of particle-attached thalli, of which 0.6-3.0 $\times 10^{8}$ are mature. These estimates are broadly consistent with the minimal ruminal enumeration of $0.9-8.4 \times 10^{8}$ thallus forming units (zoospores plus thalli) reported for the same animals (Theodorou et al. 1990).

A weakness in this life-cycle model is that the research from which values were taken was not conducted with a view to satisfying model requirements. Although all parameters could have been determined in the same laboratory, the amount of work involved would be prohibitive. Even if the assumptions on which the model is based are correct, the parameter values were obtained in different laboratories using a variety of techniques and this will undoubtedly have an impact on model results. In general, the modeller is constrained to obtain the majority of parameters from the literature. In previous papers, we have illustrated the positive effect of a symbiosis between modelling and experimentation on the improvement of our understanding of ruminant nutrition (Dijkstra \& France, 1995). The life-cycle model clearly indicates that data on the time spent in each life cycle and on rate of death are scarce resulting in a wide range of numerical values having to be set for these parameters. For better quantification, more data on life cycle parameters are required.

\section{Quantifying microbial growth and growth yield}

Physical model systems of microbial ecosystems have often been employed in attempts to understand microbial metabolism and microbial interactions. The mathematical equations describing these model systems are helpful in discerning key parameters of microbial growth and metabolism. In most physical model systems, microbial cultures are in balanced growth (Koch, 1994). A balanced growth is obtained when extensive properties, including RNA, DNA and cell number, increase regularly with time. The mathematical representation of growth and metabolism in these model systems is well documented in the literature (Pirt, 1975; Fredrickson, 1977; Bazin, 1981). Physical analogues of the rumen ecosystem can be classified into open and closed systems (Pirt, 1975). In an open system, all materials that constitute the system may enter and leave it, whereas in the closed system some essential part of the system cannot both enter and leave it. Examples of the closed and open system are the simple batch culture and the chemostat (continuous flow culture), respectively. The rumen ecosystem may be considered an open system when the ruminant is eating. During periods of rest, an essential part of the system (the feed, which provides the substrates for microbial growth) does not enter the system and the system may be considered closed for this period. In these periods of rest, secretion of substrates (for example, in saliva) and exchange and net absorption (for example, water, VFA) across the rumen wall continues. Hence, some researchers prefer to describe the rumen as semicontinuous rather than closed (Wolin, 1979). Solutions to the mathematical equations describing the chemostat (a steady-state system) are of the type I solutions. The differential equations describing the batch cultures may be solved analytically (type II solutions) as described below.

\section{Batch cultures}

If various conditions for biomass growth in batch culture are met (Pirt, 1975), the differential equations describing the dynamic behaviour of microbial biomass $(X, \mathrm{~g})$ and substrate $(S, \mathrm{~g})$ at time $t$ are: 


$$
\begin{aligned}
\mathrm{d} X / \mathrm{d} t & =0,0 \leqslant t<L \\
& =\mu X, t \geqslant L,
\end{aligned}
$$

and:

$$
\begin{aligned}
\mathrm{d} S / \mathrm{d} t & =0,0 \leqslant t<L \\
& =-q X, t \geqslant L,
\end{aligned}
$$

where $\mu(/ \mathrm{h})$ denotes specific growth rate (which in batch culture is equal to the maximum growth rate), $q$ (g S/g $X$ per h) denotes metabolic quotient for substrate utilization, and $L$ is the growth lag (h). When $\mu$ is constant, equations (7) can be integrated analytically to give:

$$
\begin{aligned}
X & =X_{0}, 0 \leqslant t<L \\
& =X_{0} e^{\mu(t-L)}, t \geqslant L,
\end{aligned}
$$

where $X_{0}$ is initial biomass. From this equation, it is clear that biomass obeys constant exponential growth in the batch culture, as long as substrate concentrations are not limiting. Logarithmic transformation of the equation and plotting the log biomass against time $(\geqslant L)$ gives a line with slope equal to $\mu$. Russell \& Baldwin (1978) determined values for maximum growth rate of some rumen bacteria. They observed large differences between bacterial species and between substrates. For example, maximum specific growth rate on glucose varied between $0.45 / \mathrm{h}$ for Megasphaera elsdenii and $2.04 / \mathrm{h}$ for Streptococcus bovis. With sucrose, which is theoretically expected to provide the same intracellular intermediates as glucose, maximum specific growth rate was only $0 \cdot 14$ /h for $M$. elsdenii but $2 \cdot 10 / \mathrm{h}$ for $S$. bovis. The high maximum growth rates of $S$. bovis help to explain the large and rapid increase in their numbers when easily degradable sugars are abundantly available. The main drawback of the batch culture is that it is a closed system without outflow of microbial material. Thus, data follow a growth curve with a number of phases (lag phase, exponential phase, stationary phase, death phase), which are not found to the same extent within the rumen ecosystem.

The survival of a species in a mixed culture also depends on other factors, including its growth yield and affinity for the substrate. The growth yield ( $Y, \mathrm{~g}$ biomass/g substrate) provides a means of expressing quantitatively the nutrient requirements of an organism:

$$
Y=-\mathrm{d} X / \mathrm{d} S .
$$

The yield is of particular interest for predicting the amount of microbial protein synthesized per unit of organic matter degraded in the rumen as applied in protein evaluation systems (see $\mathrm{p}$. 80). Also, it can be shown by using equations (7), (8) and (10) that the metabolic quotient $q$ may be expressed as:

$$
q=\mu / Y .
$$

$Y$ is a constant, reproducible quantity when conditions are maintained constant. Integration of equation (10) over the range $X_{0}$ to $X_{m}$ gives:

$$
X_{m}-X_{0}=Y S_{0}
$$

where $X_{m}$ is maximum biomass and $S_{0}$ is the initial value of $S$. Hence a plot of maximum biomass concentration against initial substrate concentration is a straight line with slope $Y$. However, whilst growth rates in batch cultures are virtually unaffected by substrate concentration since substrate concentrations remain high during the exponential growth phase, in vivo concentrations of soluble substrates are often low with the main exception being immediately after feeding. Assuming that substrate consumption follows enzyme kinetics, it can be shown that the specific growth rate $\mu$ will vary with substrate concentration $[S](g / l)$ : 


$$
\mu=\mu_{m} /\left(1+K_{S} /[S]\right)
$$

where $\mu_{m}(/ \mathrm{h})$ is the maximum value of $\mu$, obtained when $[S] » K_{S}$, and $K_{S}(\mathrm{~g} / \mathrm{l})$ is the saturation constant. This equation is known as the Monod equation since Monod (1942) first demonstrated this relationship empirically. The equation is analogous to the Michaelis-Menten equation of enzyme kinetics. The parameter $K_{S}$ gives a measure of the affinity of the organism for $S$, and is equal to growth-limiting substrate concentration at half-maximal specific growth rate. $K_{S}$ values can be determined using various methods (Pirt, 1975) and are generally low. Therefore, the peak in soluble substrates that may occur shortly after feeding (for example, the peak in concentration of soluble sugars (Clapperton \& Czerkawski, 1969) or peptides (Chen et al. 1987)) is because the amount of microbial biomass and the associated metabolic rate is not enough to utilize all the substrate immediately. In that case, soluble material (although generally assumed to be metabolized very rapidly) may be washed out from the rumen and escape fermentation. For example, the Dutch protein evaluation system assumes that a fixed $5 \%$ of the soluble fraction of protein (mainly peptides and amino acids) escapes rumen fermentation and contributes to the bypass protein (Tamminga et al. 1994). From the equations given above, it may be hypothesized that the actual escape is not a fixed percentage of intake, but depends on the initial amount of biomass and the metabolic activity of the microbes present. The prediction of escape is the subject of rumen simulation models (type III solution) (see p. 81). Such a quantitative analysis may also be useful in helping explain the presence (Chen et al. 1987) or absence (Williams \& Cockburn, 1991) of peptide accumulation in rumen fluid.

\section{Microbial interactions in vitro}

Mathematical models of the rumen ecosystem often rely on information obtained from studies in axenic cultures or co-cultures, assuming that the principles elucidated from simple systems apply to the more complex rumen ecosystem. The survival of species in the rumen can be predicted by mathematical models using data obtained in axenic cultures. An example is the growth of Selenomonas ruminantium and Bacteroides ruminicola with a single growth-limiting substrate (Fig. 3) based on data from axenic cultures (Russell \& Baldwin, 1979; Russell et al. 1979). With glucose as a single common growth-limiting substrate, S. ruminantium will eliminate $B$. ruminicola (Fig. 3(a)), because, whatever the glucose concentration, $\mu$ of the former is always higher than that of the latter. If the substrate is maltose, the growth curves intersect at a maltose concentration of $0.54 \mathrm{mg} / \mathrm{l}$ at which point both species can co-exist.

Not surprisingly, many factors will control competition and allow a wider range of survival. Wimpenny (1981) demonstrated that two organisms with intersecting Monod growth curves may survive in an environment in which the nutrient concentrations vary, but survival is in spatially different niches. Using a mathematical model, it was shown that the niche for an organism with a low maximum growth rate but a high substrate affinity would be spatially more distant from the source of the substrate than the niche of an organism with a high growth rate and a low substrate affinity. Alternatively, if the growth of micro-organisms is limited by the relative availability of substrate surface (see Chesson \& Forsberg (1997) for a discussion on techniques to estimate relative availability of surface area), the results of competition may be predicted using the Monod equations but replacing $S$ by the relative surface area $S_{r}\left(\mathrm{~mm}^{2}\right.$ surface area/mg solid substrate) and $K_{s}$ by the affinity constant for surface area $K_{s r}\left(\mathrm{~mm}^{2}\right.$ surface area/mg solid substrate). An example of the observed and simulated effect of surface area on growth of micro-organisms is given by France et al. (1990). They described a batch culture in 

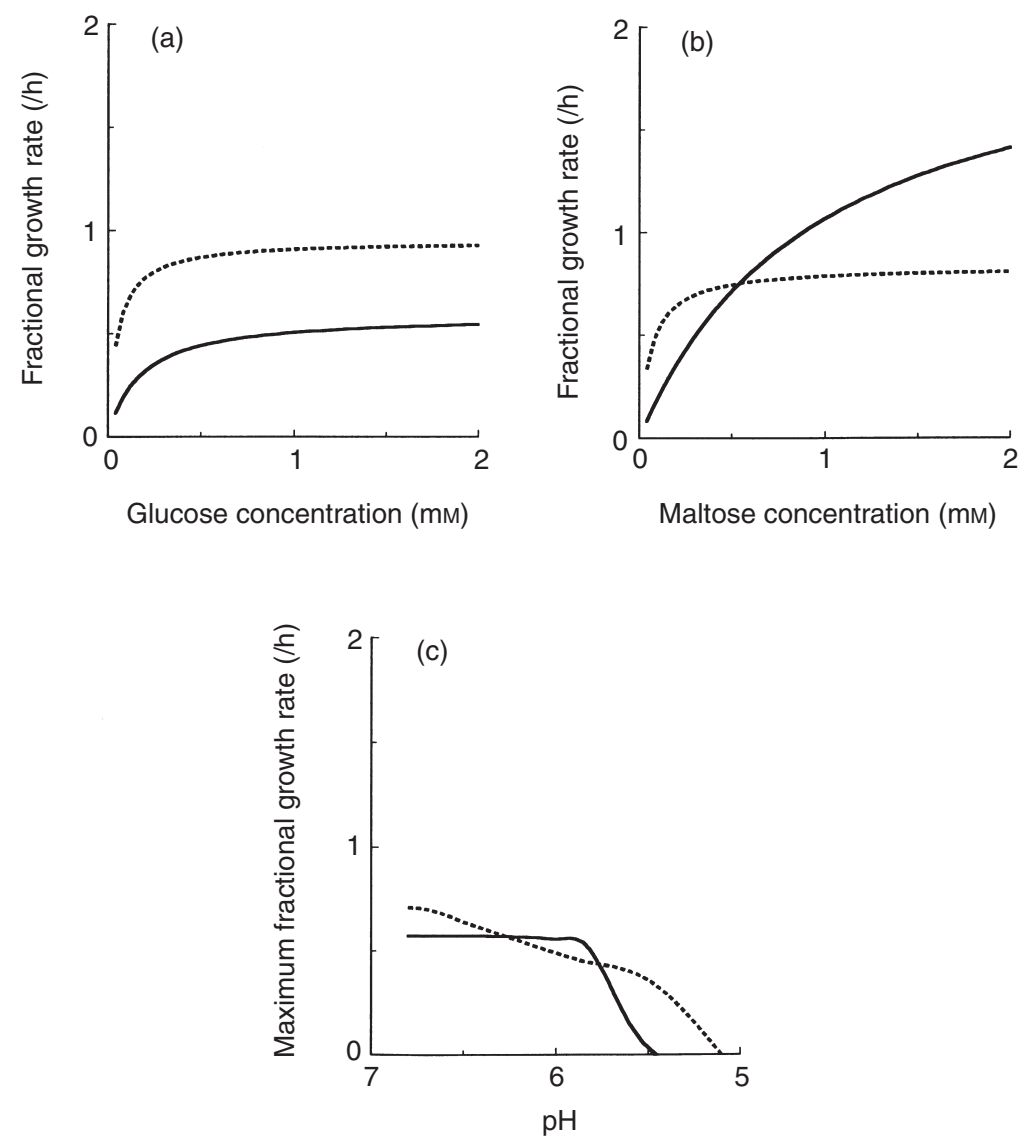

Fig. 3. Growth and competition for substrate with Bacteroides ruminicola $(-)$ and Selenomonas ruminantium (---) in relation to type and concentration of substrate and $\mathrm{pH}$. Growth on glucose (a), growth on maltose (b), maximum specific growth rate as affected by $\mathrm{pH}$ (c) when volatile fatty acid concentration is 40 mm. (Data from Russell \& Baldwin (1979) and Russell et al. (1979).)

which wheat straw particles of different sizes were fermented by bacterial- or fungal-enriched inoculae and gas production profiles were recorded as a measure of substrate degradation rates. With bacterial-enriched inoculae, the gas production rate was lower when wheat straw particle size was increased, whereas experimental fungal fermentations did not show a relationship between gas produced and particle size. Such findings are in line with simulated profiles for degradation by surface erosion (mode of attack of bacteria) and by complete invasion (mode of attack of fungi) (France et al. 1990). Since various plant tissues differ widely in ratio of exposed surface area to cell wall volume, such variation is expected to affect the abundance of microbial species that differ in their mode of attack (Lopez et al. 1993). In co-cultures, the fungal mode of attack reduces mechanical resistance of particles (Fonty et al. 1999), allowing increased bacterial attack on the damaged particles and a possible co-existence of both fungi and bacteria. Further information on modelling effects of surface area and particle size can be found in Dijkstra \& France (1997).

Competition for the same growth-limiting substrate can be controlled by the faster-growing of the two species inhibiting its own growth rate through a product $P(\mathrm{~g})$. If growth on $S$ is 
associated with production of $P$ that competitively inhibits the uptake of $S$, the equation that describes the specific growth rate is:

$$
\mu=\mu_{m} /\left(1+\left(1+[P] / J_{P}\right) K_{s} /[S]\right)
$$

where $[P]$ is the concentration of the inhibitor $(\mathrm{g} / \mathrm{l})$ and $J_{P}(\mathrm{~g} / \mathrm{l})$ denotes an inhibition constant. A co-culture of two species will become self-regulating and stable if the specific growth rate of the faster-growing species is higher than that of the slower-growing species when $[P]$ is zero. Knowledge on various inhibitory factors produced by micro-organisms in the rumen is limited (Dehority \& Tirabasso, 2000). Bacteriocins (antibacterial peptides and proteins characterized by their ability to inhibit strains of bacteria) may have a key role in bacterial population dynamics (Riley, 1998). A competitive advantage will be obtained by the bacteriocin-producing strains by inhibiting or killing bacteria in the same environment competing for the same substrates (Pagie \& Hogeweg, 1999). Other obvious and important inhibitors of growth are the endproducts of fermentation, VFA. The free acid form can pass through the microbial cell membrane and affect the proton motive force gradient across microbial cell membranes. Some bacterial species however may decrease their intracellular $\mathrm{pH}$ to maintain a relatively low $\mathrm{pH}$ gradient across the cell membrane and to prevent VFA anion accumulation in the cell (Kashket, 1987). According to the Henderson-Hasselbalch equation, a higher fraction of the VFA is present in the free acid form when $\mathrm{pH}$ is decreased, and in the rumen, VFA and $\mathrm{pH}$ of rumen fluid are related (Tamminga \& Van Vuuren, 1988). An example of the effect of $\mathrm{pH}$ at VFA concentration of $40 \mathrm{~mm}$ on the $\mu_{m}$ with glucose of $S$. ruminantium and B. ruminicola is given in Fig. 3(c). This self-inhibitory type of interaction has been shown to be of crucial importance in mathematical models of mixed cultures to stabilize the ecosystem and prevent simulated disappearance of one of the species (Fredrickson, 1977). Dijkstra (1994) applied this auto-inhibition principle in a rumen model of the type III solution that represents the metabolism of amylolytic and fibrolytic bacteria and of protozoa in the rumen. Stable coexistence under a wide range of dietary inputs was achieved by including the inhibitory effect of a relationship between substrate availability and protozoal death rate.

Another way of controlling competition is achieved when the faster-growing species produces a growth activator for the other species, a form of commensalism (for a mathematical description, see Pirt, 1975). A notable area of interactions between species of the rumen microbial ecosystem is the cross-feeding of substrates. For example, a number of bacterial and fungal species hydrolysing hemicellulose do not utilize the products of this hydrolysis, whereas others do utilize the products but are unable to hydrolyse hemicellulose (for review, see Wolin et al. 1997). Cross-feeding of reduced intermediates (especially hydrogen) is another significant example. Whilst cross-feeding does not necessarily change the maximum specific growth rates or saturation constants of rumen microbes, the type of fermentation endproduct formed may be changed drastically. Unfortunately, rumen models that predict the profile of VFA formed in the rumen have not been based on the established mathematical principles to describe cross-feeding, but depend on empirical relationships between type of substrate degraded and type of VFA formed (for review, see Dijkstra \& Bannink, 2000). In rumen simulation models, only limited attention has been given to explicit representation of the different microbial groups and microbial interactions. Often only one state variable, representing the microbial biomass as a whole, is included. For example, in developing a rumen simulation model, Baldwin (1995) aimed at the representation of one pool of micro-organisms, but was forced to distinguish between microbes degrading starch and sugars and microbes degrading fibre to avoid incorrect interactions between fibre and starch degradation. Besides, such a simplification may partly explain the prediction inaccuracies of rumen models (for example, see Dijkstra et al. (1998a) for a 
review on the consequences of various mathematical descriptions of protein evaluation systems on predicted duodenal protein supply). We feel that the use of well-established mathematical principles, which have served to describe and understand the dynamics of microbial populations in various ecosystems, should form the basis of mechanistic rumen simulation models to help quantify and understand the complex relationships.

\section{Quantifying the contribution of rumen micro-organisms to nutrient supply of the host}

The metabolic activity of the rumen microbial population is the major determinant of rumen fermentation and consequently of the profile of nutrients that are available for absorption and ultimately for production. At present, feed evaluation systems are based largely on empirical models that usually do not represent the metabolism of micro-organisms in the rumen. There is an apparent contradiction between the extensive work on mathematical representation of microbial metabolism in physical analogues of the rumen and the simple representation adopted in most whole-rumen function models. With increasing knowledge of rumen metabolism and computer power, the mechanistic rumen models that are based on the principles described earlier will likely form the basis of future feed evaluation systems (Baldwin, 1995; Hanigan et al. 1997; AFRC, 1998). Since these mechanistic models usually consist of a number of non-linear differential equations that describe the dynamics of the system, it is not possible to solve the set of equations analytically. These models are type III models that have to be solved numerically using integration routines such as Euler's method or the Runge-Kutta methods, available in several software packages. In addition, several of these software packages (for example, Advanced Continuous Simulation Language; Mitchell and Gauthier Associates, 1995) provide optimization routines to estimate parameters in a set of differential equations applied to various data (Oldick et al. 2000). In the remainder of the present paper, we illustrate the contribution of rumen simulation models to increased quantitative knowledge of rumen fermentation.

\section{Microbial protein supply}

Mechanistic models of rumen function in cattle describe microbial protein supply based on the amount and type of available organic matter (OM), the utilization of OM for microbial growth and non-growth processes, and, to a limited extent, microbial interactions (Baldwin et al. 1987; Danfær, 1990; Dijkstra et al. 1992, 1996; Dijkstra, 1994; Lescoat \& Sauvant, 1995). For example, the differential equation describing the change in microbial biomass with time $(\mathrm{d} M i / \mathrm{d} t$, $\mathrm{kg} / \mathrm{d}$ ) in the Baldwin et al. (1987) model is:

$$
\mathrm{d} M i / \mathrm{d} t=P_{M i, M i G r}-U_{M i, M i I n},
$$

where $P_{M i, M i G r}(\mathrm{~kg} / \mathrm{d})$ is the production of microbial biomass from degradation of substrates, and $U_{M i, M i I n}(\mathrm{~kg} / \mathrm{d})$ is the outflow of microbial biomass from the rumen. The production of microbial biomass is calculated from a series of mostly non-linear equations, which describe the rate of degradation of various substrates and the ATP requirement per unit of growth. Such a series of equations cannot be integrated analytically so special programming languages are usually used for numerical integration. In the rumen simulation models, other differential equations describe the change with time of fibre, starch, sugars, lipid and protein. The rumen system is thus described by a set of differential equations that are dependent on each other. The type III 
solution to such a system of differential equations allows evaluation of the effects of changes in an aspect of interest on the various state variables in the system.

The amount of substrate that is available for microbial metabolism is a key factor in the quantity of microbial protein formed. This principle is well recognized in current protein evaluation systems, in which terms such as rumen fermentable OM or fermentable metabolizable energy largely determine the amount of microbial protein formed. Whilst the protein evaluation systems adopt fixed amounts of available substrate for a particular feedstuff, it is well known that this amount really depends on factors including the retention time of feed in the rumen, the availability of other nutrients that may stimulate or inhibit substrate degradation, etc. (Firkins, 1996). The mathematical description of microbial growth in physical analogues provides a framework for quantifying the variation in level of substrate degradation. From equations (8), it is clear that the amount of microbial biomass and the metabolic activity of the microbes determine the rate of utilization of substrate, and mechanistic models apply these principles to understand the various interactions and predict the substrate availability. The availability of easily degradable carbohydrates may impair degradation of fibre. In the updated model of Baldwin et al. (1987), $\mathrm{pH}$ affects fibre degradation and $\mathrm{pH}$ itself is predicted from the concentration of lactate and VFA (Argyle \& Baldwin, 1988). Thus, fermentation of starch and sugars, which may lead to large levels of VFA and lactate in the rumen fluid, decreases $\mathrm{pH}$ in this representation, and hence affects the fermentation of fibre. The prediction of $\mathrm{pH}$, which is not just an important determinant of substrate degradation in high-producing dairy cattle but also of microbial non-growth (maintenance) energy costs (Shi \& Weimer, 1992), remains a challenge though (Allen, 1997). Next to prediction, mechanistic models provide additional insight into the contribution of microbial species or microbial groups towards substrate degradation. Bacteria, protozoa and fungi all contribute to plant-cell-wall degradation in the rumen, but the quantitative contributions of each group to degradation remains largely unclear. Such contributions are usually measured in vitro (for example, Lee et al. 2000) and the results have to be interpreted and translated to quantify the contribution in vivo. Dijkstra (1994) used data from in vivo and in vitro studies on protozoal and bacterial metabolism, and by representing the various interactions between protozoa and bacteria, was able to quantify the contributions of both groups to fibre degradation in the rumen (Dijkstra \& Tamminga, 1995). The results of the simulations indicate a protozoal contribution to ruminal fibre degradation on a variety of diets of 5-35\%. Relatively high simulated protozoal contributions were obtained with diets high in starch and sugars fed at low levels of feed intake. With such diets, defaunation would be expected to decrease fibre degradation to a larger extent than diets that are high in fibre, and this is confirmed by in vivo studies on defaunation in sheep (Ushida \& Jouany, 1990; Ushida et al. 1990). Thus, the development and application of this simulation model helped explain conflicting results on the effect of defaunation on fibre degradation in the rumen.

Another example is the interaction between protein availability and degradation of carbohydrates. This interaction is not only important in situations where the quality of the feed and levels of $\mathrm{N}$ are poor (mainly in the tropics and subtropics), but is also an issue in areas of intensive farming in the West, where concerns about high levels of $\mathrm{N}$ excretion to the environment by cattle constrain an efficient capture of $\mathrm{N}$ from the feed into endproducts (Tamminga, 1996). Degradation of OM in the rumen is depressed when the availability of $\mathrm{N}$ is low (Smith, 1979), probably because $\mathrm{N}$ deficiency impairs rumen microbial growth (for review, see Clark et al. 1992) and the resultant decrease in the amount of microbial biomass reduces substrate degradation (see equations 8). However, rumen bacteria are efficient scavengers of $\mathrm{N}$ sources, and ammonia concentrations above some $20-50 \mathrm{mg} / \mathrm{l}$ do not stimulate microbial growth further in vivo (Clark et al. 1992). The saturation kinetics adopted in most rumen simulation models, with 
a mathematical representation analogous to equation (13), also results in rapidly decreased marginal responses of microbial growth to increased availability of ammonia or other $\mathrm{N}$ sources. These models may therefore be useful tools in predicting the optimal levels of $\mathrm{N}$ supplementation when the basal diet is deficient in N, as demonstrated by Dijkstra et al. (1996) for sugarcanebased diets. This non-linear approach contrasts with the current empirical protein evaluation systems that adopt a fixed cut off level of $\mathrm{N}$ supply relative to energy supply, below which microbial synthesis is impaired.

Next to substrate degradation, the growth yield is the major determinant of microbial protein synthesized. In the classical approach, the overall use of substrates by growing microbes can be divided into substrate utilization for non-growth (maintenance) purposes and for biomass increase. Based on this partitioning, the biomass yield $Y$ is given by the double reciprocal equation of Pirt (1965):

$$
1 / Y=M_{e} / \mu+1 / Y_{\max },
$$

where $M_{e}$ is the maintenance coefficient (g substrate/g biomass per h) and $Y_{\max }$ (g biomass/g substrate) is the maximum growth yield with regard to $S$. The influence of specific growth rate, maintenance coefficient, and presence or absence of preformed monomers is illustrated in Fig. 4. In absence of preformed monomers, a higher proportion of the carbohydrates taken up by the microbes than in presence of monomers will be used for incorporation into microbial biomass. Hence, the growth efficiency per unit carbohydrate utilized and the growth rate is lower in absence of preformed monomers. The $M_{e}$ for rumen microbes as derived by Isaacson et al. (1975) (0.05 g glucose/g microbial DM per h) is frequently applied in rumen simulation models. However, $M_{e}$ varies with bacterial species and growth conditions (Hespell \& Bryant, 1979). In particular, energetic uncoupling can occur because the potential of microbes to produce energy from catabolic processes is in excess of their potential to use that energy for biosynthe-

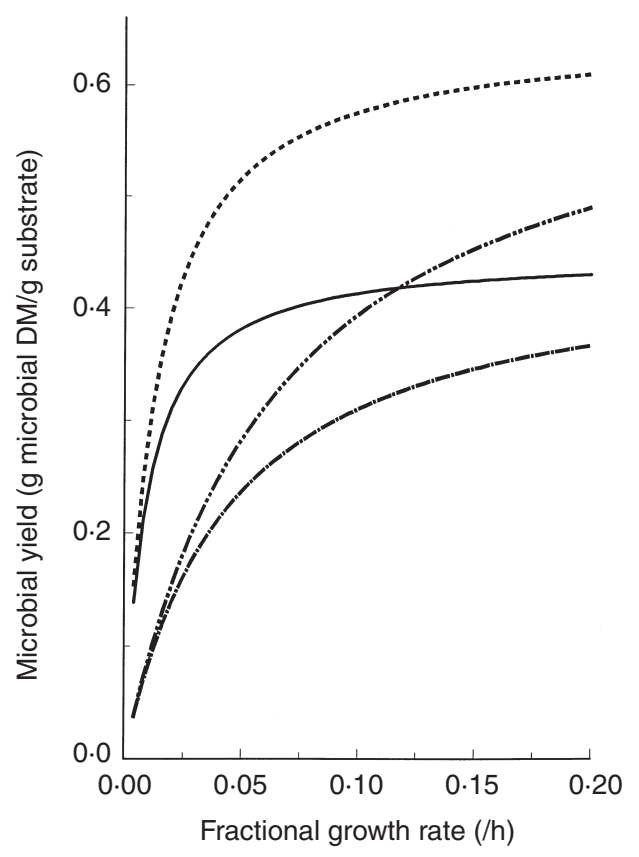

Fig. 4. Effect of specific growth rate, maintenance requirement $(M ; g$ carbohydrate/g microbial DM per h; low $M=0.02$, high $M=$ $0.10)$ and maximum growth yield ( $Y_{\text {max }} ; \mathrm{g}$ microbial DM/g carbohydrate; in presence $\left(Y_{\max }=0.65\right)$ or absence $\left(Y_{\max }=0.45\right)$ of preformed monomers) on microbial yield applying equation (16). (---), $M=0.02$ and $Y_{\max }=0.65 ;(-), M=0.02$ and $Y_{\max }=0.45$; $(-\cdots), M=0.10$ and $Y_{\max }=0.65 ;(-\cdot-), M=$ 0.10 and $Y_{\max }=0.45$. 
sis purposes when availability of non-carbohydrate substrates is limited. Increased utilization of energy for non-growth purposes has been demonstrated in various situations, including a lack of K, ammonia and amino acids relative to carbohydrates (Hespell \& Bryant, 1979). The effect of energetic uncoupling has been represented in the models of Baldwin et al. (1987) and Dijkstra et al. (1992, 1996). In this representation, a Michaelis-Menten type relationship is used that increases the utilization of carbohydrates for non-growth purposes when $\mathrm{N}$ sources are limiting.

There is even less agreement on the value of $Y_{\max }$. Both theoretical calculations (Hespell \& Bryant, 1979) and in vivo observations (Rooke \& Armstrong, 1989) show that growth yield is increased when peptides or amino acids are substituted for ammonia. However, the improvement in growth yield when all the $\mathrm{N}$ required is provided by amino acids rather than ammonia in various models is $19 \%$ (Russell et al. 1992), $59 \%$ (Dijkstra et al. 1992) and $77 \%$ (Baldwin et al. 1987).

Another major factor involved in $Y$ is the recycling of microbial protein within the rumen. Recycling of microbial $\mathrm{N}$ in the rumen is mainly due to the activities of the protozoa and varies between 20-90\% of gross microbial N synthesis (for review, see Firkins, 1996). Results of a simulation study indicated that the level of intake and composition of the diet causes large variation in microbial recycling due to protozoal metabolism within the rumen (Dijkstra et al. $1998 b)$. Such a variation has a significant impact on $Y$. If $70 \%$ of $\mathrm{N}$ requirements are met by ammonia and $30 \%$ by preformed amino acids, $3.0 \mathrm{~g}$ OM is required to synthesize $1 \mathrm{~g}$ microbial protein (Dijkstra et al. 1992). However, the synthesis of $1 \mathrm{~g}$ microbial protein flowing from the rumen requires $3.8 \mathrm{~g}$ OM when recycling is $20 \%$ of gross synthesis, and $30.0 \mathrm{~g}$ when recycling is $90 \%$ of gross synthesis. Such simulation results thus indicate the significance of protozoal activities on net yield of microbial protein.

Finally, equation (16) shows the importance of specific growth rate $\mu$ of microbes towards $Y$. In chemostat cultures, $\mu$ is equal to the dilution rate. Hence in most rumen simulation models, an increase in the fractional passage rate in vivo is assumed to increase the efficiency of microbial synthesis. In addition, the fractional passage rate may be a major determinant of the composition and amino acid profile of bacteria being washed out of the rumen (Rodriguez et al. 2000). The main exception to this approach is that of the Cornell system (see Alderman et al. (2001) for a detailed description of the Cornell system). In this system, equation (16) is adopted but $\mu$ is replaced by the fractional degradation rate of the substrate. From equations (8) and (11) (type II solution models) it is clear that the fractional degradation rate itself depends on the amount of microbes present and the microbial activity, and this approach is biologically unrealistic. However, if the fractional rate of degradation also affects the size or the specific gravity of particles, a higher fractional degradation rate may coincide with elevated fractional passage rates since smaller, denser particles have a higher chance of passage from the rumen (Kaske $e t$ al. 1992). Most rumen simulation models consider a continuous feed input and hence resemble the continuous culture system. A preliminary analysis of the effect of feeding frequency (three or six meals per $d$ or continuous feeding) and of fractional degradation rate upon microbial efficiency, using a model based on the equations described in the present paper, indicated that both factors did not affect microbial efficiency (Dijkstra et al. 2000). However, although the Monod equations can predict growth rate and substrate utilization in steady-state systems and in systems that appear to be near steady state, deviations from the equations may occur under transient conditions (Bazin et al. 1976). Therefore, the modelling of effect of microbial metabolism on microbial efficiency when animals are meal-fed requires further research. 


\section{Lactate production and utilization}

The fermentation pattern in the rumen is sensitive to diurnal nutrient intake and feeding frequency. In addition, degradation rate differs between nutrients and from one nutrient source to another (Tamminga et al. 1990). This variation in nutrient availability, combined with the range in substrate preferences of different microbial species, leads to fluctuations in the rumen microbial population structure. For example, ingestion of a meal rich in soluble carbohydrates encourages the proliferation of bacteria such as S. bovis and lactobacilli (Mackie \& Gilchrist, 1979). These bacteria produce lactic acid as an endproduct of anaerobic fermentation, which is subsequently utilized by bacteria such as $M$. elsdenii and the protozoa. This cyclic pattern of lactate production and utilization, with the associated rise and fall in the populations of $S$. bovis and M. elsdenii, holds true for diets in the normal range.

However, accumulation of rumen lactic acid for animals fed large quantities of degradable starch or sugars occurs where the rate of lactic acid production exceeds the capacity of the lactate utilizing microbes for uptake (Owens et al. 1998). The endproducts of microbial species may change depending on substrate availability and $\mathrm{pH}$. Moreover, large variation occurs in the sensitivity to $\mathrm{pH}$ of both lactate-utilizing and lactate-producing microbes (Therion et al. 1982). Thus, the prediction of lactic acid dynamics is complex and current feed evaluation systems for dairy cows, because of their static and factorial nature, are unable to address the complex interrelationships in the rumen that give rise to lactic acidosis. A dynamic mechanistic approach to feed evaluation demonstrates a greater capacity for describing such rumen fermentation processes although to date these models have given only minimal consideration of ruminal lactate metabolism (Dijkstra et al. 1992; Baldwin, 1995). Therefore, the microbial components of a mathematical model to simulate the metabolism of lactic acid in the rumen is described below, based on the biological outlines given above. Such a description illustrates the interrelationships between experimental and modelling research and also illustrates the use of type III solutions.

\section{Model construction}

The model to simulate the metabolism of lactic acid in the rumen is a modification of the model presented by Dijkstra (1994). The principal nutrient fluxes within the model are as described by Dijkstra (1994) with key additional elements shown in Fig. 5. Nutrient inputs to the model are a product of feed characterization data and a pulse function representing meal feeding (France $e t$ al. 1982). The model comprises four microbial groups, namely the fibrolytic bacteria, amylolytic lactic acid-producing bacteria $\left(\mathrm{Ba}_{\mathrm{LP}}\right)$, amylolytic lactic acid-utilizing bacteria $\left(\mathrm{Ba}_{\mathrm{LU}}\right)$ and the protozoa $(\mathrm{Po}) . \mathrm{Ba}_{\mathrm{LU}}$ are able to utilize both lactate and amylolytic hexose as energy sources. Therefore, $\mathrm{Ba}_{\mathrm{LU}}$ also represent those bacteria neither producing nor utilizing lactate. Po also have the ability to utilize either hexose or lactate for maintenance and growth (Williams \& Coleman, 1997). To reflect the ability of $\mathrm{Ba}_{\mathrm{LU}}$ and Po to utilize either lactate or hexose as an energy substrate, wherever hexose metabolism occurs involving these two microbial groups a similar transaction is present for lactate. The utilization of substrate $S$ (for example, lactate, hexose, amino acids) by a microbe group is described according to Michaelis-Menten saturation kinetics similar to equation (13). In a previous section (p. 77), the problems to obtain simulated coexistence of microbial groups using the same limiting substrate have been described. In the original model by Dijkstra (1994), auto-inhibition effects were introduced to achieve stable coexistence between Po, amylolytic and fibrolytic bacteria. In the modified version, $\mathrm{Ba}_{\mathrm{LU}}$ or $\mathrm{Ba}_{\mathrm{LP}}$ could disappear, for example when high-fibre diets low in amylolytic hexose are fed, or where 


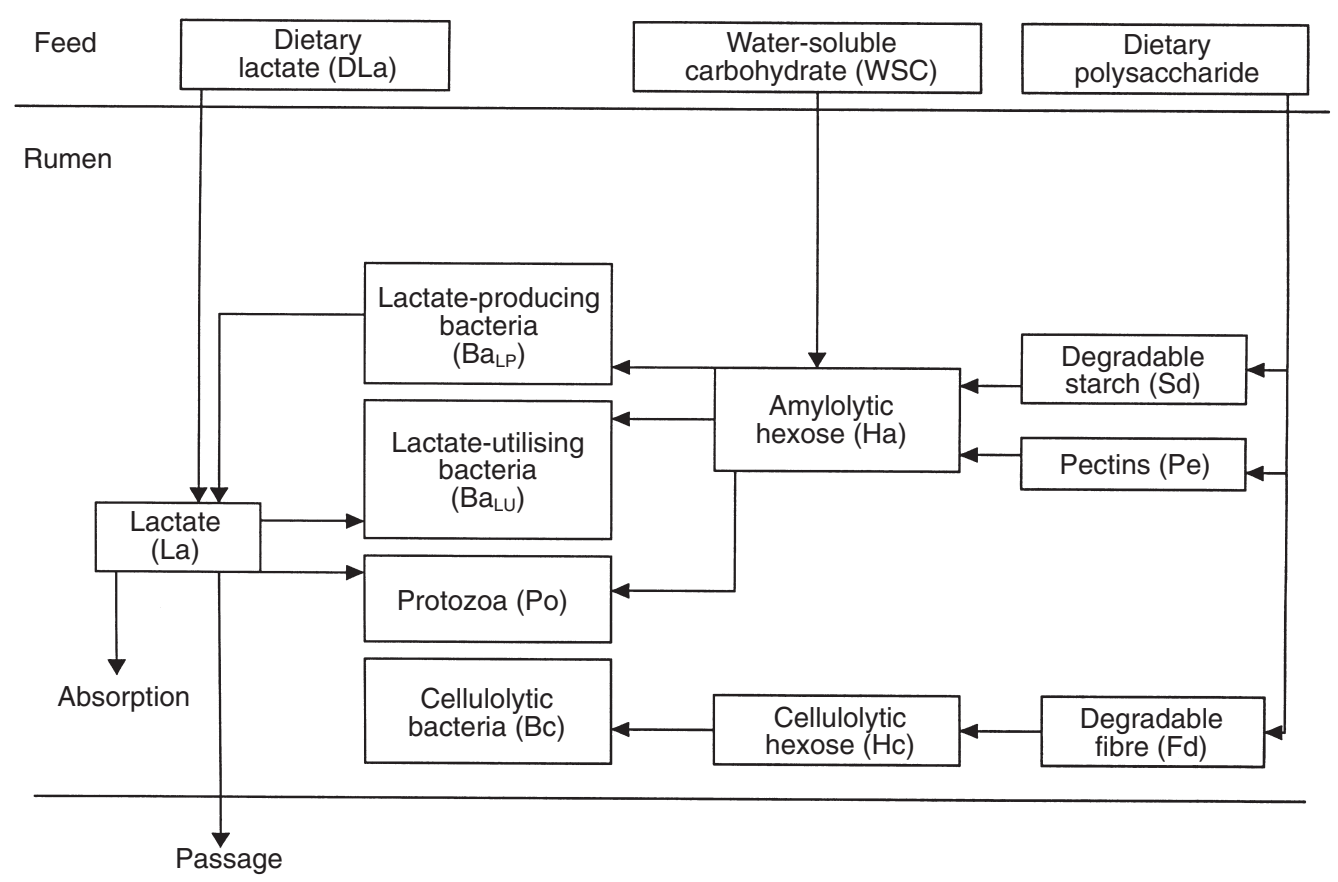

Fig. 5. Diagrammatic representation of microbial groups and their energy substrates within the type III rumen model of lactic acid dynamics.

long periods of fasting are simulated. In reality, microbial adherence to the rumen epithelium and cross-feeding of nutrients prevents such major simplifications of microbial population structure. Therefore, minima were arbitrarily set so that no amylolytic bacterial group was allowed to decline to less than $2 \%$ of the total amylolytic bacterial population.

It is generally accepted that $S$. bovis is the major bacterial species producing lactate in the rumen, with lactobacilli proliferating only in the most acidic conditions (Stewart, 1992). Therefore, the metabolism of $\mathrm{Ba}_{\mathrm{LP}}$ is taken to resemble that of $S$. bovis. The lactate-producing bacteria ferment amylolytic hexose as their sole source of energy. However, they metabolize a varying proportion of fermented hexose to either lactic acid or VFA depending on specific growth rate and rumen $\mathrm{pH}$ (Russell \& Baldwin, 1979; Stewart, 1992). Therefore, the proportion of hexose fermented to lactate by $\mathrm{Ba}_{\mathrm{LP}}\left(Y_{L a}\right)$ is assumed to increase as specific growth rate increases and as $\mathrm{pH}$ declines as follows:

$$
Y_{L a}=Y_{L a_{\min }}+\left(Y_{L a_{\max }}-Y_{L a_{\min }}\right) /\left(1+\left(p H / K_{p H Y_{L a}}\right)^{\theta}{ }_{p H Y_{L a}}\right),
$$

where $Y_{L a_{\min }}$ and $Y_{L a_{\max }}$ are the minimum and maximum ratio of hexose fermented to lactate respectively, $K_{p H Y_{L a}}$ is the $\mathrm{pH}$ of the rumen fluid where $Y_{L a}$ is half maximal, and $\theta_{p H Y_{L a}}$ is a steepness parameter. These parameters were estimated from the in vitro data of Russell \& Baldwin (1979). $K_{p H Y_{L a}}$ varies with specific growth rate of $\mathrm{Ba}_{\mathrm{LP}}$ according to:

$$
K_{p H Y_{L a}}=K_{p H Y_{L a_{\text {min }}}}+\left(K_{p H Y_{L a \max }}-K_{p H Y_{L a_{\min }}}\right) /\left(1+2 \hat{\mu}_{Y_{L a}} /\left(\mu_{Y_{L a}}-\mu c_{Y_{L a}}+\left|\mu_{Y_{L a}}-\mu c_{Y_{L a}}\right|\right)\right)
$$

where $K_{p H Y_{L a_{\text {min }}}}$ and $K_{p H Y_{L a_{m a x}}}$ are the minimum and maximum $\mathrm{pH}$ between which $K_{p H Y_{L a}}$ varies according to specific growth rate, $\mu_{Y_{L a}}$ and $\mu c_{Y_{L a}}$ are the specific growth rate (/h) and the critical specific growth rate $(/ \mathrm{h})$ respectively, below which $K_{p H Y_{L a}}$ equals $K_{p H Y_{L a_{\text {min }}}}$, and $\hat{\mu}_{Y_{L a}}$ is the specific 
growth rate $(/ \mathrm{h})$ where $Y_{L a}$ is half maximal. Parameter estimates were obtained by fitting the data of Russell \& Dombrowski (1980) to equation (18). In view of the high $\mu_{m}$ values of $S$. bovis observed in vitro (Russell \& Baldwin, 1979), $\mu_{m}$ of $\mathrm{Ba}_{\mathrm{LP}}$ was set at a higher value $(2 \cdot 0 / \mathrm{h})$ than that calculated by Dijkstra et al. (1992) for $\mathrm{Ba}_{\mathrm{LU}}(0 \cdot 6 / \mathrm{h})$. Hexose affinity constants for $\mathrm{Ba}_{\mathrm{LP}}$ were calculated assuming that $\mathrm{Ba}_{\mathrm{LP}}$ have an affinity six times lower than $\mathrm{Ba}_{\mathrm{LU}}$ during competition for hexose. Therefore, where hexose concentration is low, $\mathrm{Ba}_{\mathrm{LU}}$ maintain a competitive advantage, but at high concentrations $\mathrm{Ba}_{\mathrm{LP}}$ predominate due to their higher maximum growth rate, similar to the competition between micro-organisms depicted in Fig. 3(b).

The $\mathrm{Ba}_{\mathrm{LU}}$ represents mixed amylolytic bacteria during normal fermentation conditions, whereas when rumen lactate concentration increases relative to hexose, the characteristics of $\mathrm{Ba}_{\mathrm{LU}}$ shift towards those associated with lactate-utilizing bacteria. Counotte et al. (1981) showed that $M$. elsdenii accounted for the majority (60-85\%) of lactate fermentation in the rumen. Therefore, lactate fermentation parameters for this group are based on those reported for M. elsdenii. The $\mu_{m}$ during growth on hexose is $0 \cdot 6 / \mathrm{h}$ (Dijkstra et al. 1992) but on lactate $1 \cdot 0 / \mathrm{h}$, identical to that reported by Russell \& Baldwin (1979) for M. elsdenii grown on lactate. Therefore, $\mathrm{Ba}_{\mathrm{LU}}$ have the opportunity to grow faster when $M$. elsdenii predominate under conditions of high lactate availability, representing the change in microbial structure following the feeding of substantial quantities of degradable carbohydrate. Lactate affinity constants were set relative to typical basal lactate concentration $(0.1-0.2 \mathrm{~mm})$ and the comparative affinity of $\mathrm{Ba}_{\mathrm{LU}}$ for hexose assuming a basal hexose concentration of $2 \mathrm{~mm}$. Therefore, changes in the relative lactate and hexose concentrations bring about the appropriate shift in energy substrate utilization.

In recognition of the significance of lactate as a substrate for protozoal metabolism, this pool was adapted from Dijkstra (1994) to allow growth on both hexose and lactate. The maximum lactate uptake rate was assigned a value intermediate to the protozoal lactate uptake rates observed by Chamberlain et al. (1983) and lactate disappearance rates observed by Newbold et al. (1987). Published estimates of protozoal affinity for lactate uptake $\left(K_{\text {LaLaPo }}\right)$ are not available. Therefore, $K_{\text {LaLaPo }}$ was set arbitrarily at thirty times basal lactate concentration in view of the preference of protozoa for hexose (Williams \& Coleman, 1997) unless lactate concentrations are high and the entodiniomorphid protozoa predominate. The holotrich protozoa show virtually no capacity for lactate uptake (Newbold et al. 1987).

Inputs to the lactic acid pool are directly from the feed and from fermentation of hexose by $\mathrm{Ba}_{\mathrm{LP}}$. Outputs from this pool are from passage with the rumen fluid, absorption through the rumen wall and uptake followed by fermentation for growth and for non-growth purposes by $\mathrm{Ba}_{\mathrm{LU}}$ and Po. As with VFA, the absorption of lactic acid increases as rumen $\mathrm{pH}$ declines. However, the rate of lactic acid absorption from the rumen is much slower than that of VFA (Møller et al. 1997). Lactic acid absorption parameters related to lactic acid concentration and $\mathrm{pH}$ were set based on the in vivo data of Williams \& Mackenzie (1964) and the in vitro results from Møller et al. (1997). Fermentation of lactic acid to VFA is calculated using a constant stoichiometry taken from sheep in the radioisotope study of Gill et al. (1986). Where one mole of lactate fermented yields 0.95 mol VFA (Baldwin, 1995), the stoichiometric coefficients are 0.571 acetate, 0.333 propionate and 0.0487 butyrate. This type III solution model was solved using a fourth-order fixed-step-length Runge-Kutta method (Mitchell and Gauthier Associates, 1995).

\section{Model evaluation and application}

To test the efficacy of the model in predicting lactic acid dynamics in the rumen, published feeding trials have been simulated. Mackie et al. (1984) used sheep to investigate the metabo- 
lism of lactic acid for high-concentrate, intermediate, high-roughage, and lucerne hay diets twice daily (DM intake $1.5 \mathrm{~kg} / \mathrm{d}$ ), and administered DL-[2-14]lactate to measure lactate production and utilization rates in the rumen. Fig. 6 demonstrates the reasonable agreement between observed and predicted lactate production and utilization rates for the high-concentrate diet of Mackie et al. (1984). Simulated time to peak rates of production and utilization are slower than observed, although the difference is small $(<0 \cdot 3 \mathrm{~h})$. The predicted delay between peak production and utilization is approximately half that observed, but the monitoring frequency for the observed data of only every $0.25 \mathrm{~h}$ prevents a comprehensive comparison. Compared with observations, the simulated peak utilization rate is some $25 \%$ lower although the decline from the peak is delayed relative to observed. From 150 min post feeding simulated lactate production is lower than observed by a factor of $8(1.20 \mathrm{vs} .0 .15 \mathrm{mmol} / \mathrm{l}$ per $\mathrm{h})$. This indicates that the very low simulated basal lactate concentrations result from underprediction of lactate production rather than overprediction of utilization in the rumen. As noted earlier in the section on microbial protein supply (p. 81), deviations from the saturation kinetics may occur under transient conditions and thus the use of saturation kinetics in this model may have contributed to errors in the dynamic behaviour.

The simulated fate of lactate was examined using an experiment of Counotte et al. (1983). They measured lactate concentrations in the rumen of dairy cows fed grass hay and a concentrate diet of $6 \mathrm{~kg} \mathrm{DM} / \mathrm{d}$ twice daily (total DM intake $21 \mathrm{~kg} / \mathrm{d}$ ) to lactating Holstein cows. The predicted peak lactate concentration $(25 \mathrm{mM})$ was slightly lower than that observed $(29 \mathrm{~mm})$. The fate of lactate was dependent upon its concentration in the rumen (Fig. 7). $\mathrm{Ba}_{\mathrm{LU}}$ was the major sink for rumen lactate at both peak and basal lactate concentrations. However, the relative contribution of $\mathrm{Ba}_{\mathrm{LU}}$ declined immediately post feeding and again as lactate concentration approached its peak. The simulated contribution of protozoa to lactate utilization was most significant as lactate concentration approached peak levels. Apart from the first 10 min post feeding, the contributions of passage and absorption to the removal of lactate from the rumen were only between 2-9\% and 1-2\%, respectively. Therefore, the simulations are in agreement with Gill et al. (1986) who accounted for $90 \%$ of total lactate flux through fermentation to VFA in grass silage-fed sheep. Hence, in support of Gill et al. (1986), it would seem that the direct contribution of rumen lactate to glucose synthesis by the tissues is minimal.

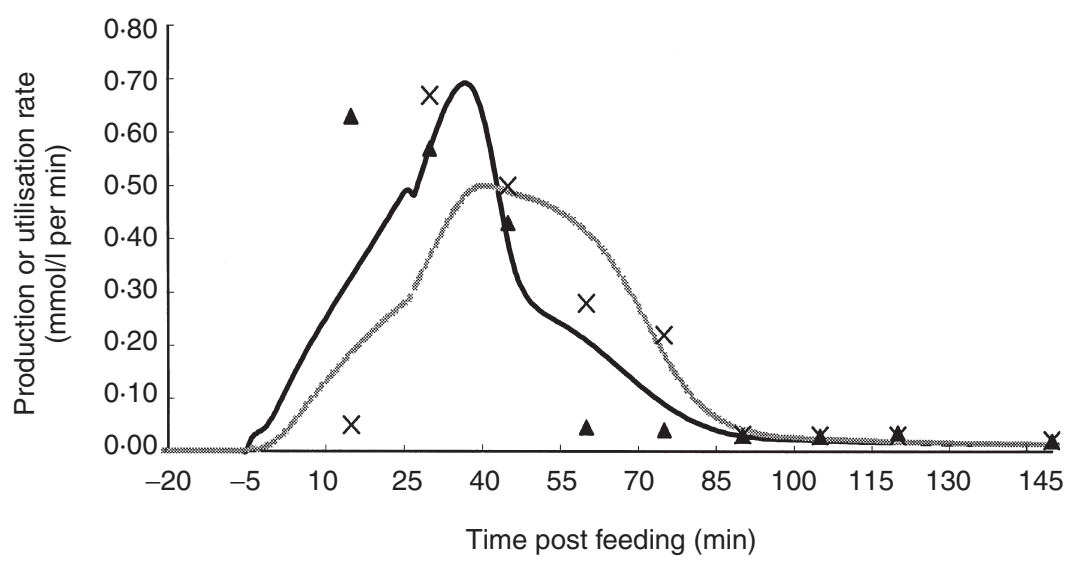

Fig. 6. A comparison of simulated and observed production $(-, \mathbf{\Lambda})$ and simulated and observed utilization $($ (senewe,$X$ ) of lactic acid in the rumen of sheep fed the high-concentrate diet of Mackie et al. (1984). 


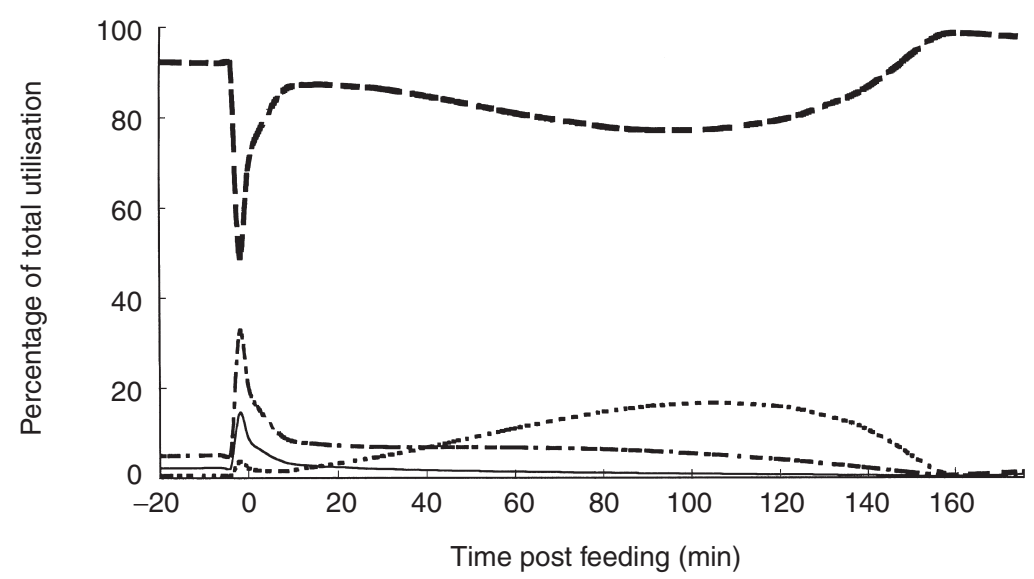

Fig. 7. Simulated fate of lactate within the rumen after feeding $6 \mathrm{~kg}$ concentrate to a dairy cow for the diet of Counotte et al. (1983). (- - ), Amylolytic lactic acid-utilizing bacteria; (‥), protozoa; (-), absorption; $(-\cdot-\cdot)$, passage.

In experiments with cattle, Malestein et al. (1984) showed that the risk of lactic acidosis was not only correlated with levels of easily degradable carbohydrates in the diet, but also correlated with the level of soluble protein. The effect of soluble protein is striking, because lactic acid is not a major product of protein fermentation. Previously, we have described how dynamic mechanistic modelling may be a tool to increase understanding and explain responses. In order to investigate these unexpected results, the model was used to simulate the effects of changing levels of soluble protein for the diet fed by Counotte et al. (1983). Where the fraction of soluble protein was increased by $25 \%$ at the expense of rumen undegradable protein, the simulated peak lactate concentration increased marginally by $2.3 \%$ from $25 \mathrm{~mm}$ to $26 \mathrm{~mm}$ (observed peak value was $29 \mathrm{~mm}$ ). However, when soluble protein was reduced by $25 \%$ the simulated peak lactate concentration declined by $12.0 \%$ to $22 \mathrm{~mm}$. This confirms the observations by Malestein et al. (1984) and can be explained by the increase in specific growth rate of $\mathrm{Ba}_{\mathrm{LP}}$ as protein availability increases. This increase in growth rate leads to an increase in the fraction of hexose fermented to lactate (equations 17 and 18) as well as the total number of $\mathrm{Ba}_{\mathrm{LP}}$. Whilst $\mathrm{Ba}_{\mathrm{LU}}$ are also dependent upon levels of soluble protein availability for growth, their maximal specific growth rate is only half of that of $\mathrm{Ba}_{\mathrm{LP}}$ and this lower maximal growth rate limits the effect of increasing protein availability on rumen lactate utilization. In addition to the effect described by Malestein et al. (1984), the model shows a diminishing returns response as soluble protein becomes non-limiting to amylolytic bacterial growth. Overall, this dynamic mechanistic modelling exercise of the type III solution based on a system of differential equations has identified areas where biological knowledge is lacking, has provided an understanding of nutritional factors leading to lactic acidosis and could be a basis to evaluate ruminant diets for their potential acidosis risks.

\section{Conclusions}

Mathematical models are powerful tools to integrate various aspects of rumen microbial metabolism. They assist in better understanding the substrate utilization, endproduct formation, and 
interactions between populations of micro-organisms. In the present paper, the dynamic, mechanistic models have been classified according to the type of solution. When the system is in steady state, solutions may be obtained by solving the algebraic expressions that are obtained by setting the differentials to zero (type I solution). When the system is not in steady state, linear differential equations may be integrated analytically (type II solutions) or non-linear equations integrated numerically (type III solutions). Various applications described in the present paper show that the models need not necessarily be complex and very detailed to contribute to better understanding. The development and evaluation of models will indicate areas where current knowledge is insufficient. Even when data are unavailable, testing of hypotheses using mathematical models will stimulate new ideas and experimental approaches. It is essential that the models are based on sound mathematical and biological principles in order to contribute to development of knowledge of microbial contribution to rumen function.

\section{Acknowledgements}

The research of J. Dijkstra has been made possible by a fellowship of the Royal Netherlands Academy of Arts and Sciences. Financial support provided by MAFF Livestock (LS3608) is appreciated by the authors.

\section{References}

AFRC (1998) Responses in the yield of milk constituents to the intake of nutrients by dairy cows. AFRC Technical Committee on Responses to Nutrients. Report no. 11. Nutrition Abstracts and Reviews 68B, 937-989.

Alderman G, France J \& Kebreab E (2001) A critique of the Cornell Net Carbohydrate and Protein System with emphasis on dairy cattle. 1. The rumen model. Journal of Animal and Feed Sciences 10, 1-24.

Allen MS (1997) Relationship between fermentative acid production in the rumen and the requirement for physically effective fiber. Journal of Dairy Science 80, 1447-1462.

Argyle JL \& Baldwin RL (1988) Modeling of rumen water kinetics and effects of rumen pH changes. Journal of Dairy Science 71, 1178-1188.

Baldwin RL (1995) Modeling Ruminant Digestion and Metabolism. New York: Chapman and Hall.

Baldwin RL, Thornley JHM \& Beever DE (1987) Metabolism of the lactating cow. II. Digestive elements of a mechanistic model. Journal of Dairy Research 54, 107-131.

Bazin MJ (1981) Mixed culture kinetics. In Mixed Culture Fermentations, pp. 25-51 [ME Bushell and JH Slater, editors]. London: Academic Press.

Bazin MJ, Saunders PT \& Prosser JI (1976) Models of microbial interactions in the soil. Critical Reviews in Microbiology 4, 463-498.

Chamberlain DG, Thomas PC \& Anderson FJ (1983) Volatile fatty acid proportions and lactic acid metabolism in the rumen in sheep and cattle receiving silage diets. Journal of Agricultural Science 101, 47-58.

Chen G, Sniffen CJ \& Russell JB (1987) Concentration and estimated flow of peptides from the rumen of dairy cattle: effects of protein quantity, protein solubility and feeding frequency. Journal of Dairy Science 70, 983-992.

Chesson A \& Forsberg CW (1997) Polysaccharide degradation by rumen micro-organisms. In The Rumen Microbial Eco-system, 2nd ed., pp. 329-381 [PN Hobson and CS Stewart, editors]. London: Blackie Academic and Professional.

Clapperton JL \& Czerkawski JW (1969) Methane production and soluble carbohydrates in the rumen of sheep in relation to the time of feeding and the effects of short-term intraruminal infusions of unsaturated fatty acids. British Journal of Nutrition 23, 813-826.

Clark JH, Klusmeyer TH \& Cameron MR (1992) Microbial protein synthesis and flows of nitrogen fractions to the duodenum of dairy cows. Journal of Dairy Science 75, 2304-2323.

Counotte GHM, Lankhorst A \& Prins RA (1983) Role of DL-lactic acid as an intermediate in rumen metabolism of dairy cows. Journal of Animal Science 56, 1222-1235.

Counotte GHM, Prins RA, Janssen RHAM \& DeBie MJA (1981) Role of Megasphaera elsdenii in the fermentation of DL-[2-13C]lactate in the rumen of dairy cattle. Applied and Environmental Microbiology 42, 649-655.

Danfær A (1990) A Dynamic Model of Nutrient Digestion and Metabolism in Lactating Dairy Cows. PhD Dissertation. National Institute of Animal Science, Foulum, Denmark.

Dehority BA \& Tirabasso PA (2000) Antibiosis between ruminal bacteria and ruminal fungi. Applied and Environmental Microbiology 66, 2921-2927. 
Dhanoa MS, France J \& Siddons RC (1989) On using a double-exponential model for describing faecal marker concentration curves. Journal of Theoretical Biology 141, 247-257.

Dijkstra J (1994) Simulation of the dynamics of protozoa in the rumen. British Journal of Nutrition 72, 679-699.

Dijkstra J \& Bannink A (2000) Analyses of modelling whole rumen function. In Feeding Systems and Feed Evaluation Models, chapter 13, pp. 299-322 [MK Theodorou and J France, editors. Wallingford: CAB International.

Dijkstra J \& France J (1995) Modelling and methodology in animal science. In Proceedings Fourth International Workshop on Modelling Nutrient Utilisation in Farm Animals, pp. 9-18 [A Danfaer and P Lescoat, editors]. Foulum, Denmark: National Institute Animal Science.

Dijkstra J \& France J (1997) Modelling interactions among micro-organisms in the reticulo-rumen. In Progress in Microbial Ecology, 7th International Symposium on Microbial Ecology, pp. 297-309 [MT Martins, MIZ Sato, JM Tiedje, LCN Hagler, J Dobereiner and PS Sanchez, editors]. Sao Paulo: International Committee on Microbial Ecology/Brazilian Society for Microbiology.

Dijkstra J, France J \& Davies DR (1998a) Different mathematical approaches to estimating microbial protein supply in ruminants. Journal of Dairy Science 81, 3370-3384.

Dijkstra J, France J, Dhanoa MS \& Lopez S (2000) Simulation of substrate degradation, microbial synthesis and gas production in the gas production technique and in vivo. In Gas Production: Fermentation Kinetics for Feed Evaluation and to Assess Microbial Activity, pp. 42-43. Edinburgh: British Society of Animal Science.

Dijkstra J, France J, Neal HDStC, Assis AG, Aroeira LJM \& Campos OF (1996) Simulation of digestion in cattle fed sugar cane: model development. Journal of Agricultural Science, Cambridge 127, 231-246.

Dijkstra J, France J \& Tamminga S (1998b) Quantification of the recycling of microbial nitrogen in the rumen using a mechanistic model of rumen fermentation processes. Journal of Agricultural Science, Cambridge 130, 81-94.

Dijkstra J, Neal HDStC, Beever DE \& France J (1992) Simulation of nutrient digestion, absorption and outflow in the rumen: model description. Journal of Nutrition 122, 2239-2256.

Dijkstra J \& Tamminga S (1995) Simulation of the effects of diet on the contribution of rumen protozoa to degradation of fibre in the rumen. British Journal of Nutrition 74, 617-634.

Firkins JL (1996) Maximizing microbial protein synthesis in the rumen. Journal of Nutrition 126, 1347S-1354S.

Fonty G, Chavarot M, Lepetit J, Canistro J, Favier R (1999) Mechanical resistance of wheat straw after incubation in cultures of rumen cellulolytic micro-organisms. Animal Feed Science and Technology 80, 297-307.

France J, Dijkstra J, Dhanoa MS \& Baldwin RL (1998) Biomathematical applications in animal nutrition. Journal of the Franklin Institute 335B, 241-258.

France J, Theodorou MK \& Davies D (1990) Use of zoospore concentrations and life cycle parameters in determining the population of anaerobic fungi in the rumen eco-system. Journal of Theoretical Biology 147, 413-422.

France J \& Thornley JHM (1984) Mathematical Models in Agriculture. London: Butterworths.

France J, Thornley JHM \& Beever DE (1982) A mathematical model of the rumen. Journal of Agricultural Science, Cambridge 99, 343-353.

Fredrickson AG (1977) Behavior of mixed cultures of micro-organisms. Annual Review of Microbiology 31, $63-87$.

Gill M, Siddons RC \& Beever DE (1986) Metabolism of lactic acid isomers in the rumen of silage-fed sheep. British Journal of Nutrition 55, 399-407.

Gordon GLR \& Phillips MW (1998) The role of anaerobic gut fungi in ruminants. Nutrition Research Reviews 11, 133-168.

Hanigan, MD, Dijkstra J, Gerrits WJJ \& France J (1997) Modelling post-absorptive protein and amino acid metabolism in the ruminant. Proceedings of the Nutrition Society 56, 631-643.

Hespell RB \& Bryant MP (1979) Efficiency of rumen microbial growth: influence of some theoretical and experimental factors on $\mathrm{Y}_{\mathrm{ATP}}$. Journal of Animal Science 49, 1640-1659.

Hobson PN \& Stewart CS (1997) The Rumen Microbial Eco-system, 2nd ed. London: Blackie Acedemic and Professional.

Isaacson HR, Hinds FC, Bryant MP \& Owens FN (1975) Efficiency of energy utilization by mixed rumen bacteria in continuous culture. Journal of Dairy Science 58, 1645-1659.

Kashket ER (1987) Bioenergetics of lactic acid bacteria: cytoplasmic pH and osmotolerance. FEMS Microbiology Reviews 46, 233-244.

Kaske M, Hatiboglu S \& Von Engelhardt W (1992) The influence of density and size of particles on rumination and passage from the reticulo-rumen of sheep. British Journal of Nutrition 67, 235-244.

Koch AL (1994) Growth measurement. In Methods for General and Molecular Bacteriology, pp. 248-277 [P Gerhardt, RGE Murray, WA Wood and NR Kreig, editors]. Washington: American Society for Microbiology Press.

Krause DO, Smith WJM, Ryan FME, Mackie RI \& McSweeney CS (1999) Use of 16S-rRNA based techniques to investigate the ecological succession of microbial populations in the immature lamb rumen: Tracking of a specific strain of inoculated Ruminococcus and interactions with other microbial populations in vivo. Microbial Ecology 38, 365-376.

Lee SS, Ha JK \& Cheng K-J (2000) Relative contributions of bacteria, protozoa, and fungi to in vitro degradation of orchard grass cell walls and their interactions. Applied and Environmental Microbiology 66, 3807-3813.

Lescoat P \& Sauvant D (1995) Development of a mechanistic model for rumen digestion validated using the duodenal flow of amino acids. Reproduction Nutrition Developpement 35, 45-70.

Lopez S, Murison SD, Travis AJ \& Chesson A (1993) Degradability of parenchyma and sclerenchyma cell walls isolated at different stages from a newly extended maize internode. Acta Botanica Neerlandica 42, 165-174. 
Mackie RI \& Gilchrist FMC (1979) Changes in lactate-producing and lactate-utilising bacteria in reaction to $\mathrm{pH}$ in the rumen of sheep during stepwise adaptation to a high-concentrate diet. Applied and Environmental Microbiology 38, 422-430.

Mackie RI, Gilchrist FMC \& Heath S (1984) An in vivo study of ruminal micro-organisms influencing lactate turnover and its contribution to volatile fatty acid production. Journal of Agricultural Science, Cambridge 103, 37-51.

Malestein A, Van't Klooster AT, Prins RA \& Counotte GHM (1984) Concentrate feeding and ruminal fermentation 3. Influence of concentrate ingredients on $\mathrm{pH}$, on DL-lactic acid concentration in rumen fluid of dairy cows and on dry matter intake. Netherlands Journal of Agricultural Science 32, 9-21.

Mitchell and Gauthier Associates (1995) Advanced Continuous Simulation Language (ACSL). User's guide/Reference manual, version 11. MGA Software.

Møller PD, Diernaes L, Sehested J, Hyldgaard-Jensen J \& Skadhauge E (1997) Lactate transport across the bovine rumen epithelium in vitro. Journal of Veterinary Medicine A44, 31-38.

Monod J (1942) Recherches sur la Crossance des Cultures Bactériennes, 2nd ed. Paris, France: Hermann.

Mountfort DO \& Orpin CG (1995) Anaerobic Fungi. New York: Marcel Dekker Inc.

Newbold CJ, Williams AG \& Chamberlain DG (1987) The in-vitro metabolism of D,L-lactic acid by rumen microorganisms. Journal of the Science of Food and Agriculture 38, 9-18.

Oldick BS, Firkins JL \& Kohn RA (2000) Compartmental modeling with nitrogen-15 to determine effects of degree of fat saturation on intraruminal N recycling. Journal of Animal Science 78, 2421-2430.

Owens FN, Secrist DS, Hill WJ \& Gill DR (1998) Acidosis in cattle: a review. Journal of Animal Science 76, $275-286$.

Pagie L \& Hogeweg P (1999) Colicin diversity: a result of eco-evolutionary dynamics. Journal of Theoretical Biology 60, 3688-3696.

Pirt SJ (1965) The maintenance energy of bacteria in growing cultures. Proceedings of the Royal Society London 163B, 224-231.

Pirt SJ (1975) Principles of Microbe and Cell Cultivation. Oxford: Blackwell Scientific Publications.

Riley MA (1998) Molecular mechanisms of bacteriocin evolution. Annual Review of Genetics 32, 255-278.

Rodriguez CA, Gonzalez J, Alvir MR, Repetto JL, Centeno C \& Lamrani F (2000) Composition of bacteria harvested from the liquid and solid fractions of the rumen of sheep as influenced by feed intake. British Journal of Nutrition 84, 369-376.

Rooke JA \& Armstrong DG (1989) The importance of the form of nitrogen on microbial protein synthesis in the rumen of cattle receiving grass silage and continuous intrarumen infusions of sucrose. British Journal of Nutrition 61, 113-121.

Russell JB \& Baldwin RL (1978) Substrate preferences in rumen bacteria: evidence of catabolite regulatory mechanism. Applied and Environmental Microbiology 36, 319-329.

Russell JB \& Baldwin RL (1979) Comparison of substrate affinities among several rumen bacteria: a possible determinant of rumen bacterial competition. Applied and Environmental Microbiology 37, 531-536.

Russell JB \& Dombrowski DB (1980) Effect of pH on the efficiency of growth by pure cultures of rumen bacteria in continuous culture. Applied and Environmental Microbiology 39, 604-610.

Russell JB, O`Connor JD, Fox DG, Van Soest PJ \& Sniffen CJ (1992) A net carbohydrate and protein system for evaluating cattle diets: I. Ruminal fermentation. Journal of Animal Science 70, 3551-3561.

Russell JB, Sharp WM \& Baldwin RL (1979) The effect of pH on maximum bacterial growth rate and its possible role as a determinant of bacterial competition in the rumen. Journal of Animal Science 48, 251-255.

Shi Y \& Weimer PJ (1992) Response surface analysis of the effects of pH and dilution rate on Ruminococcus flavefaciens FD-1 in cellulose-fed continuous culture. Applied and Environmental Microbiology 58, 2583-2591.

Smith RH (1979) Synthesis of microbial nitrogen compounds in the rumen and their subsequent digestion. Journal of Animal Science 49, 1604-1612.

Stewart CS (1992) Lactic acid bacteria in the rumen. In The Lactic Acid Bacteria in Health and Disease, pp. 49-68 [BJB Wood, editor]. New York: Elsevier.

Tamminga S (1996) A review on environmental impacts of nutritional strategies in ruminants. Journal of Animal Science 74, 3112-3124.

Tamminga S, Van Straalen WM, Subnel APJ, Meijer RGM, Steg A, Wever CJG \& Blok MC (1994) The Dutch protein evaluation system: the DVB/OEB-system. Livestock Production Science 40, 139-155.

Tamminga S \& Van Vuuren AM (1988) Formation and utilization of end products of lignocellulose degradation in ruminants. Animal Feed Science and Technology 21, 141-159.

Tamminga S, Van Vuuren AM, Van der Koelen CJ, Ketelaar RS \& Van der Togt PL (1990) Ruminal behaviour of structural carbohydrates, non-structural carbohydrates and crude protein from concentrate ingredients in dairy cows. Netherlands Journal of Agricultural Science 38, 513-526.

Theodorou MK, Gill M, King-Spooner C \& Beever DE (1990) Enumeration of anaerobic chytridiomycetes as thallus forming units: novel method for quantification of fibrolytic fungal populations from the digestive tract eco-system. Applied and Environmental Microbiology 56, 1073-1078.

Therion JJ, Kistner AA \& Kornelius JH (1982) Effect of pH on growth rates of amylolytic and lactilytic bacteria. Applied and Environmental Microbiology 44, 428-434.

Ushida K \& Jouany JP (1990) Effect of defaunation on fibre digestion in sheep given two isonitrogenous diets. Animal Feed Science and Technology 29, 153-158.

Ushida K, Kayouli C, De Smet S \& Jouany JP (1990) Effect of defaunation on protein and fibre digestion in sheep fed on ammonia-treated straw-based diets with or without maize. British Journal of Nutrition 64, 765-775. 
Williams AG \& Cockburn JE (1991) Effect of slowly and rapidly degraded protein sources of the concentrations of amino acids and peptides in the rumen of steers. Journal of the Science of Food and Agriculture 56, 303-314.

Williams AG \& Coleman GS (1997) The Rumen Protozoa. In The Rumen Microbial Eco-system 2nd ed., pp. 73-139 [PN Hobson and CS Stewart, editors]. London: Blackie Academic and Professional.

Williams VJ \& Mackenzie DDS (1964) The absorption of lactic acid from the reticulo-rumen of the sheep. Australian Journal of Biological Sciences 18, 917-934.

Wimpenny JWT (1981) Spatial order in microbial eco-systems. Biological Reviews of the Cambridge Philosophical Society 56, 295-342.

Wolin MJ (1979) The rumen fermentation: a model for microbial interactions in anaerobic eco-systems. In Advances in Microbial Ecology 3, pp. 49-77 [M Alexander, editor]. New York: Plenum Press.

Wolin MJ, Miller TL \& Stewart CS (1997) Microbe-microbe interactions. In The Rumen Microbial Eco-system, 2nd ed., pp. 467-491 [PN Hobson and CS Stewart, editors]. London: Blackie Academic and Professional. 